\title{
Tactics Analysis of Attacking the Pansa FC Women's Futsal Team Yogyakarta, Indonesia
}

\author{
Yulvia Miftachurochmah ${ }^{1}$, Tomoliyus ${ }^{1,{ }^{*}}$, Salvator Nahimana ${ }^{2}$, Endang Rini Sukamti ${ }^{1}$, \\ Abdul Alim ${ }^{1}$, Fauzi \\ ${ }^{1}$ Faculty of Sport Science, Yogyakarta State University, Yogyakarta, Indonesia \\ ${ }^{2}$ Institute of Physical Education and Sport, University of Burundi, Burundi
}

Received November 25, 2020; Revised March 2, 2021; Accepted March 23, 2021

\section{Cite This Paper in the following Citation Styles}

(a): [1] Yulvia Miftachurochmah, Tomoliyus, Salvator Nahimana, Endang Rini Sukamti, Abdul Alim, Fauzi, "Tactics Analysis of Attacking the Pansa FC Women's Futsal Team Yogyakarta, Indonesia," International Journal of Human Movement and Sports Sciences, Vol. 9, No. 2, pp. 356 - 362, 2021. DOI: 10.13189/saj.2021.090225.

(b): Yulvia Miftachurochmah, Tomoliyus, Salvator Nahimana, Endang Rini Sukamti, Abdul Alim, Fauzi (2021). Tactics Analysis of Attacking the Pansa FC Women's Futsal Team Yogyakarta, Indonesia. International Journal of Human Movement and Sports Sciences, 9(2), 356 - 362. DOI: 10.13189/saj.2021.090225.

Copyright $\odot 2021$ by authors, all rights reserved. Authors agree that this article remains permanently open access under the terms of the Creative Commons Attribution License 4.0 International License

\begin{abstract}
Background: Futsal tactics are very important elements in supporting athlete performance. Purpose: This study aims to observe and analyze the tactical attack process used by the Pansa FC women's futsal team. Design/methodology/approach: This is a descriptive study with quantitative approach. The research sample was futsal team like Pansa FC, FFYK, JFA Angels, and Pansa Academy. The instruments employed in this study were Counter Attack (CA), Organized Game (OG) and Stopped Ball (SB) used to see the success rate of attacking tactics based on the finishing performance by the Pansa FC women's team during the offensive play. Data analysis with descriptive statistic used SPSS.26 version. Result showed that OG has an efficiency value of $12.66 \%$, SB has an efficiency value of $14.29 \%$, and is followed by CA which has an efficiency value of $17.28 \%$. Conclusion: Thus, based on the number of finishes, the CA is dominant. Meanwhile, based on the influence of the attacking tactics process used along with the total goals marked, CA has an efficiency value of $40 \%$, SB has an efficiency value of $10 \%$ whereas OG has an efficiency value of $50 \%$. In the wake of these results yielded, it can be concluded that the influence of the attack tactic process used along the total goals marked in such futsal game the OG tactic was more dominant.
\end{abstract}

Keywords Tactics, Attacking, Futsal, Women's Futsal

\section{Introduction}

The tactic is the concept of setting up individuals, groups, and teams according to the roles of the players in the team structure [1]. According to [2] tactics are strategies or intentions used in competition to gain sportsmanship. It is tended to be dynamic since they roughly or even always change depending on the opponent being faced and the ability of the team [3]. Tactics are reflections chiefly physical and mental on how to win against the adversarial team regardless of technical, physical, and mental components [4]. The tactic is all about how to organize the team members to work together to defeat the opponent [5]. In other words, tactics are personal tricks or skills used in competition to achieve victory either individually, in a group, or as a team [6]. The characteristics of the use of tactics according to [7] develop reasoning, creativity and make the right decisions, analyze the physical, technical and mental preparation so that the opponent does what he/she wants, seeks victory effectively and efficiently, solidifies the mental champion by controlling emotions and avoiding injuries.

Broadly attacking tactics especially in a sporting context, is defined as strategies conducted by individuals, groups, or teams against the adversary to lead and break the defense in seeking to win the match [8]. Attacking tactics is an attempt to defeat the opponent which is performed by attacking the opponent first and is also a tactic physically applied in the purpose to break the 
opponent's defense to seek victory in sports competition [9]. Meanwhile, according to [10] the attack tactic is a positional system used to attack in the game and refers to the initial formation, training, and distribution of players throughout the playing field. In the same vein, [11] also suggested that attack tactics are a positional system used to attack in playing games, and refers to the initial formation, training, and distribution of players throughout the playing arena which is carried out by individuals, groups, or teams against opponents, and subsequentially break down defenders' opponents to seek victory in sports competition.

Attack tactics can be performed either individually, in groups, or by team members [12]. A team will be able to carry out good attacking tactics with a process resulting from systematic and programmed training. The quality of the attacking tactics for the Pansa FC team is in a good period of development, but sometimes it becomes a problem when the opponent is faced with tight defensive tactics by accumulating opposing players in the defensive zone so that the opponent plays only controls counterattack system using quick breaks. The role of the coach manager is then needed to solve this problem by formulating strategies and tactics to find a way out, while the player himself should be able to apply effectively the instructions from the coach and then implement them in the game.

In a futsal game, the team players need to master futsal tactics when playing an attacking game pattern [13]. The main intention is only to attempt to dribble or to penetrate the opponent's defense and then marks a goal. The scoring process in futsal matches can occur due to an attack on the opponent's defense. In application on the playground, the moment of attacking has 2 phases, namely to build the attack and to finish the attack or mostly called finishing.

The finishing act must be put more forward in the principle of the attack because it is to know how to score goals in futsal [14]. Finishing in the game of futsal can be performed in 3 tactical attack processes, namely, by an organized game (OG), counter-attack (CA), and stopped ball (SB) [15]. Finishing is one of the most effective means of scoring goals, and it can be used as an important variable to study [16].

The purpose of this research is to analyze the process of attacking tactics which are useful in creating opportunities through finishing, to compare the process of the most used attack tactics and to consider the results of using the process. of attack tactics, comparing the process of attacking tactics mostly used that can be useful to identify which process was best used by the Pansa Futsal players so that the team crew can score more goals. As an implication, the results from this present study would contribute to improving the futsal training process.

To this end, this research can be useful to study the dynamics of futsal. For example, to determine strategies and tactics from different angles and also to identify specificities or uniqueness features of the team. In this study, it can also be useful as the team evaluation material in futsal matches so that the team would be even much better. In Indonesia, there haven't been many evaluations of team performance, especially in futsal. Therefore, the authors believe this research is important and has many advantages.

\section{Materials and Methods}

The method used for this research is descriptive observational $[17,18,19,20,21]$. In this study, the observation executed is intended to determine the technical and tactical parameters that are observed and analyzed through games or competitions. This study intends then to analyze the application of the field skills at the moment of attack when completing or finishing a futsal game that can be performed through 3 attacking processes, namely OG, CA, and SB. Sampling used a total of 48 individuals as female futsal players.

This research was conducted when the women from Pansa futsal team were awarded 3 trophy matches held in Yogyakarta by the JFA team management. The Pansa FC Team against the FFYK Team, JFA Angels, and the Pansa FC Academy have the competency in coaching sports achievements in the Special Region of Yogyakarta, Indonesia. The Pansa team is a futsal team from Yogyakarta whose players officially playing in the Indonesian Professional League. The instruments used in this study were in form of CA, OG, and SB (henceforth Counter Attack, Organized Game, and Stopped Game respectively) rubrics to analyze how many finishes can be done in one match during the attacking play at the Pansa FC Women's Futsal Team with Aiken value equal to V (0.814), while the value of instrument reliability using product-moment correlation with the value of (0.83). apart from that, the camera DSLR with serial brand Canon EOS 90D was used to record live video matches. Meanwhile, the video was analyzed using the Kinovia application.

\section{Research procedure}

a). Make observations by recording each game.

b). Make observations by playing videos using the Kinovia app and performing assessments using the instruments mentioned in the preceding section.

c). Perform data analysis from observations.

\section{Data Analysis}

The data were analyzed by the researchers using a video camera to record the matches played by the Pansa futsal team. The finishing performed by the team was all analyzed to assess the attacking tactics used by the Pansa team, which tactical attacking process among OG, CA, and SB suggested, and the finishing done whether it can 
result in a goal, or the ball hits the bar, or the ball can be pushed away by the goalkeeper, or maybe captured or intercepted by the opposing player, or the ball leaves the baseline. The video is initially set at normal speed, after which each movement will be set at a slower speed $(1 / 2$, $1 / 4$, or $1 / 8$ of normal speed) to be more accurate for analyzing the motion, ball lane, and tactics used. The presentation of the results of this study is descriptive statistics using the frequency distribution method. The results of the data were processed with the Excel 2013 application and the help of the SPSS 26 edition software. Categories and analysis criteria:

\section{Organized Game (OG)}

An organized Game in the Indonesian language is often defined as a coordinated or organized game. The OG stands for Organized Game are tactics aim to make lose the opponent's defense. In the futsal game, the possession of the ball, good movement/dribbling, and accurate passing are very important to form a good attack [22]. With that, he/she can finish readily without any hindrance from the opponent, thereby obtaining an excellent opportunity to achieve the main objective of creating goals [23]. Moreover, the $\mathrm{OG}$ tactics requires good teamwork, good communication, and good physical condition. If the futsal team players do not have good cohesion, communication, and physicality, this tactic cannot go or work smoothly [24].

\section{Counter Attack (CA)}

The counterattack known as (CA) in short is a tactic used by a team in a defensive position that can regain control of the ball from the attacking team and then develop a surprise attack with rapid and disorganized movements [25]. An influential element of this stand-out tactic is that the player must master basic techniques that are skilled and with the right mindset to make quick decisions [26].

\section{Stopped Ball (SB)}

The stopped ball henceforth (SB) can be distinguished from a ball that has stopped moving by replacing it in the original position while playing also at the beginning of this attack by organized game [27]. The stopped ball can be classified as an example of skill in defensive tactics, attacking and cornering, where movements are characterized by trained movement [28]. In this tactic, players must be able to take advantage of the opportunities created, even if these opportunities are very rare. From stopping ball, it is very effective to be used as a scoring opportunity to produce goals.

All of the above methods of attack can be assessed or evaluated. Evaluation is a strong tool to know the level of someone about the material object and formal object [29]. Apart from being able to evaluate the three ways of performing effective attack tactics to improve fitness, strength, and cardiorespiratory balance [30]. With the passage of time these three methods of attacking tactics audited above will always be developed and increase in popularity [31].

\section{Result}

The result of this research is that the Pansa FC team can make 138 finishes in 3 organized matches. The picture below depicts the final results of the 3 matches which will be explained in the table as follows:

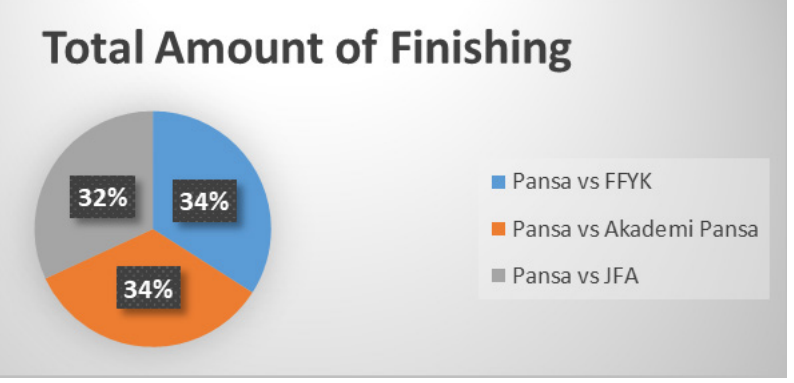

Figure 1. Total Amount of Finishing

Based on the diagram above, it can be concluded that the Pansa FC team against the FFYK team can complete $32 \%$ of the total finishes, whereas $34 \%$ of total finishes were recorded between Pansa Academy versus the JFA team.

The following is an explanation of the total finishes achieved by the Pansa FC team in 3 consecutive matches through the tactical attacking process of $\mathrm{OG}, \mathrm{CA}$, and SB.

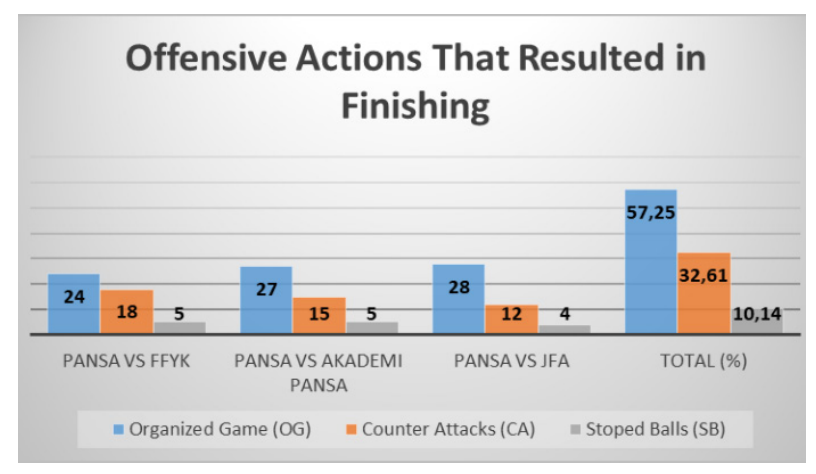

Figure 2. Offensive Actions that Resulted in Finishing

Based on the data in the diagram above, it can be concluded that the Pansa FC team versus the FFYK team, finishing through tactical system OG attack tactical process for 24 kicks, 18 AC kicks, and 5 kicks. of foot tactics. Then against Pansa Academy, the Pansa FC team was able to finish OG for 27 kicks, thanks to the CA process of attacking tactics for 15 kicks and SB tactics for 5 kicks. Meanwhile, against the JFA team, the Pansa FC team was able to complete the Olympics process for 28 kicks, 12 kicks for CA, and 4 for SB. From this data, it can be concluded that the finish is done by the dominant Pansa FC team through the process of OG attack tactics with a percentage of $57.25 \%$, the second via CA tactics 
with a percentage of $32.61 \%$, and the third via SB tactics with a percentage of $10,14 \%$.

The following is the description obtained from the total finish achieved by the Pansa FC team in 3 matches which resulted in goals, a ball on the post, a kick defended by the goalkeeper, finalization intercepted by the opponent, and an outward kick which will be explained in the diagram below.

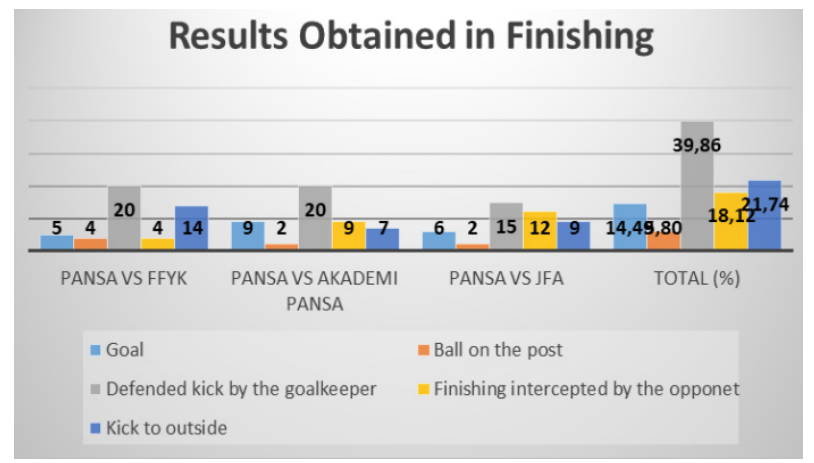

Figure 3. Result Obtained in Finishing

Based on the diagram above, it can be concluded that the finishing results obtained by the Pansa FC team against FFYK resulted in 5 goals, 4 balls on the post, 20 defended kicks by the goalkeeper, 4 finishing intercepted by the opponent, and 14 kick outside. Then against the Pansa Academy the team scored 9 goals, 2 balls on the post, 20 pushed away by the goalkeeper, 9 finishing intercepted by the opponent, and 7 kick to outside. Meanwhile, against the JFA team, the Pansa FC team scored 6 goals, 2 balls on the post, 15 defended by the goalkeeper, 12 finishing intercepted by the opponent, and 9 kicked to outside. From these data, it can be presented that $14.49 \%$ of the attacks carried out by the Pansa FC team resulted in goals, then $5.80 \%$ ball on the post, $39.86 \%$ defended and kicked away by the goalkeeper, $18.12 \%$ finishing was intercepted by the opponent, while $21.74 \%$ of the ball kicked out.

Based on the explanation showcased in diagrams 1, 2, and 3, the Pansa FC team can score 10 goals from 79 total finishing through the OG attack tactics process with a percentage of $12.66 \%$. Then by using the tactical process CA scored as many as 8 goals from 45 finishes with a percentage of $17.78 \%$. While the tactical attack process SB scored as many as 2 goals from 14 finishes with a percentage of $14.29 \%$. To be clearer, the diagram below will be presented:

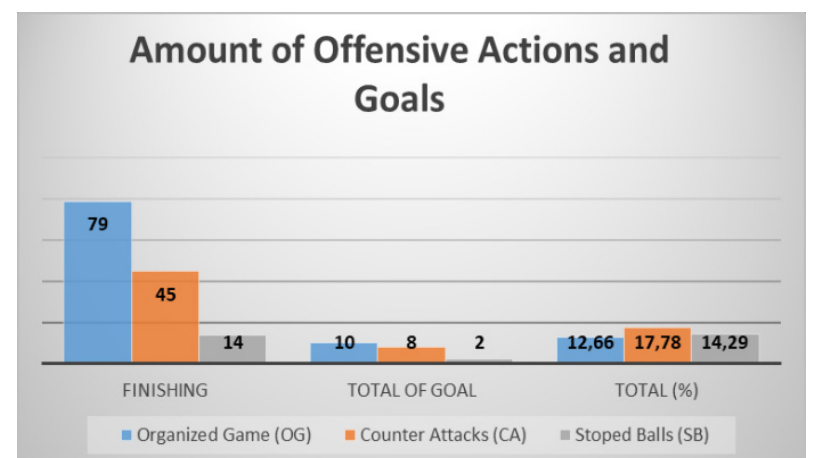

Figure 4. Number of Offensive Actions and Goals

Based on the diagram above, it can be concluded that the analysis of the goal of the Pansa FC team using the tactical attack process CA $(17.28 \%)$, followed by the stopped ball process SB (14.29\%) and finally with the OG (12.66) \%.

Analyze the effectiveness of each attacking tactic used by the Pansa FC team to mark the goal

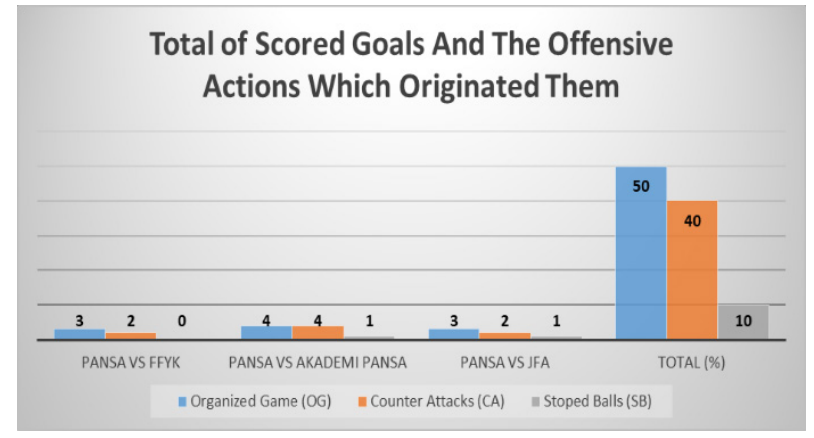

Figure 5. Total of Scored Goals and the Offensive Actions Which Originated Them

Based on the diagram above, it can be concluded that the Pansa FC team can score 20 goals in 3 matches with a goal efficiency of $50 \%$ via the organized game (OG) and then $40 \%$ via counter-attacks (CA), while $10 \%$ via Stopped Balls (SB).

\section{Discussion}

In this study, the researcher divided 3 aspects of the process of attacking tactics for analyzing, namely the use of the attacking tactics process of OG, CA, and SB. The Pansa FC team can make up to 138 finishes. Based on the research data, the researcher can analyze the Pansa FC team as follows. 


\section{a). Pansa FC vs FFYK}

According to the results, the match opposing the FFYK team and the Pansa FC team was 5-2 ahead of the FFYK team and was able to make 47 finishing, 24 finishing of the $\mathrm{OG}$ attack tactical process, 18 finishing of the CA tactical attack process and 5 finishes of the tactical SB attack process. The FFYK team includes several players from the Indonesian national team and several other professional players from the Indonesian team as well as amateur players. In the first halftime, Pansa FC scored 2 goals, while the FFYK team lose its points to score against the Pansa FC team. The two goals in the first-half time were both scored through the offensive tactical process of organized game.

In the second halftime of the game, Pansa FC scored 3 goals, two goals from the CA's offensive tactical process and the other one from the OG's offensive tactical process. Whereas the FFYK team scored 2 goals from the counterattack process. Based on the researcher's observations, the Pansa FC team was superior in terms of skills to FFYK as the FFYK team had uneven playing skills. There are players on a professional level or status and also those whose status is still an amateur player. so that they can only profit from the negligence and errors of the game played by the Pansa FC is where the FFYK team counterattack occurs.

Based on the above data, it can be concluded that the victory achieved by the Pansa FC team is an attack from the tactical attacking interaction of the organized game with a total of 3 goals scored.

\section{b). Pansa FC vs JFA}

According to the results of the analysis of the match against the JFA team, the Pansa FC team was 6-3 ahead of the JFA team and was able to make 44 finishing, 28 finishing from the OG attack tactical process, 12 finishing of the CA tactical attack process and 4 finishing of the tactical attack process SB. The JFA team was made up of several other players from the professional team in Indonesia and players from PORDA (Regional Sports Week) as well as amateur players. In the first halftime, the Pansa FC team scored 3 goals, while the JFA team scored 1 goal which took advantage of a foul committed by one of the JFA players. The JFA team takes advantage of the Stopped Ball (SB) process to score goals in the first half. The first three goals were scored by the Pansa FC team, one goal by the tactical attacking process of the organized game. There was also one goal scored by a tactical counterattacking process, another goal by a tactical attack process of the stopped ball because the Pansa FC team obtained a penalty.

In the second halftime, the Pansa FC scored 3 goals, two goals from the OG offensive tactical process and one goal from the CA offensive tactical process. While the JFA team scored 2 goals from the counterattack process. Just because the Pansa FC team was more dominant, the
Pansa FC playing freely using good team players and careful cooperation, using OG's tactical attacking process. Meanwhile, the matches played by the JFA team could only benefit from some mistakes made by the Pansa FC team. In terms of playing skills, the Pansa FC players are better than JFA players, for example in passing, controlling, and dribbling.

Based on the above data, it can be concluded that the victory achieved by the Pansa FC team was more dominant using the Organized Time Attack (OG) tactical process. Meanwhile, JFA was more dominant in the Counterattack (CA) process.

\section{c). Pansa FC vs Akademi Pansa}

The Pansa Academy is a team under the management of the Pansa FC team. In Indonesia, when a team plays in the professional league, the team is required to have a futsal academy/school. According to the results of the match analysis against the Pansa Academy, the Paansa FC team was winning 9-4 over the Pansa Akademi team to do 47 finishes, 27 finishes from the OG attack tactical process, 15 finishes from the CA attack tactical process, and 5 finishes from the SB attack tactical process. Most of the Pansa academy players are regional players or players who follow PORDA. The game against the Pansa academy was very much dominated by Pansa FC, but from the three matches that Pansa FC has played, the Pansa FC team has conceded the greatest number of bad balls as many as 4 goals, this can happen because the Pansa FC team was physicality drained by the previous match so that the team players Pansa FC made mistakes that shouldn't have happened.

In the first halftime, the Pansa FC team was able to score 3 goals. One goal was taken from a backpass ball mistake committed by Pansa Academy players, which meant the process of the goal using the SB attack tactical process. One goal was scored using CA's attacking tactical process and the other one scored using SB's attacking tactical process. Meanwhile, the Pansa Academy scored 3 goals, two goals through CA and 1 goal through OG. In the second halftime, the Pansa's goal productivity increased. The Pansa FC scored as many as 6 additional goals. Three goals were through the tactical process of attacking $\mathrm{CA}$ and three goals were also through the process of attacking OG. Meanwhile, the Pansa Academy team could only add 1 goal through CA. Based on the data above, it can be concluded that the victory obtained by the Pansa FC team when viewed from the number of goals scored, the Pansa FC was dominant in the tactical process of attacking OG and CA because they both marked 4 goals. Meanwhile, the Pansa Academy was more dominant at CA.

\section{Conclusions}

The purpose of this study was to create parameters that 
can be used in evaluating the training process in the futsal field, especially in Indonesia. Based on the number of finishes with the number of goals scored by the Pansa FC team, this CA attacking tactic process $(17.78 \%)$ has a higher effective value than OG and SB. However, if viewed from the effect of the attacking tactics process used with the total goals produced by the attacking tactics process OG $(50 \%)$, the effective value is higher than CA and SB. Thus, OG's attacking tactical process is more effective in producing goals, and from this research, we know that there is an imbalance between the number of finishes, the number of goals, and the use of the attacking tactical process itself. Therefore, it requires a more in-depth development of the tactical attack process so that the team can take advantage of the many opportunities that occur and can gain victory.

\section{Acknowledgements}

We are very grateful, appreciate, and also thank all people who contribute to this research, especially for the Pansa Woman FC players and their management.

\section{REFERENCES}

[1] Morgan, P. B. C., Fletcher, D., \& Sarkar, M. Understanding team resilience in the world's best athletes: A case study of a rugby union World Cup-winning team, Psychology of Sport and Exercise, Vol. 16, pp. 91-100, 2015 https://doi.org/http://dx.doi.org/10.1016/j.psychsport.2014.0 8.007

[2] Ayoub, K., \& Payne, K. Strategy in the Age of Artificial Intelligence, Journal of Strategic Studies, Vol. 39, No. 5-6, pp. 793-819, 2016. https://doi.org/10.1080/01402390.2015. 1088838

[3] Mitchell, S., Mitchell, S. A., Oslin, J., \& Griffin, L. Teaching sport concepts and skills: A tactical games approach, Human Kinetics Publishers, 2020.

[4] Gershgoren, L., Basevitch, I., Gershgoren, A., Brill, Y. S., Schinke, R. J., \& Tenenbaum, G. Expertise in soccer teams: A thematic inquiry into the role of shared mental models within team chemistry, Psychology of Sport and Exercise, Vol. 24, pp. 128-139, 2016. https://doi.org/http://dx.doi.org /10.1016/j.psychsport.2015.12.002

[5] Freedman, L. Strategy: A History, Oxford University Press, 2015.

[6] Davenport, T., \& Harris, J. Competing on analytics: Updated, with a new introduction: The new science of winning, Harvard Business Press, 2017.

[7] Lech, G., Chwała, W., Ambroży, T., \& Sterkowicz, S. Muscle torque and its relation to technique, tactics, sports level and age group in judo contestants, Journal of Human Kinetics, Vol. 45, No. 1, pp. 167-175, 2015 https://doi.org/10.1515/hukin-2015-0017
[8] Tabben, M., Conte, D., Haddad, M., \& Chamari, K. Technical and tactical discriminatory factors between winners and defeated elite karate athletes, International Journal of Sports Physiology and Performance, Vol. 14, No. 5, pp. 563-568, 2019. https://doi.org/10.1123/ijspp.2018-04 78.

[9] Liu, H., Gomez, M. Á., Lago-Peñas, C., \& Sampaio, J. Match statistics related to winning in the group stage of 2014 Brazil FIFA World Cup, Journal of Sports Sciences, Vol. 33, No. 12, pp. 1205-1213, 2015. https://doi.org/10.1080/0264 0414.2015.1022578.

[10] Ramos, J., Lopes, R. J., \& Araújo, D. What's Next in Complex Networks? Capturing the Concept of Attacking Play in Invasive Team Sports, Sports Medicine, Vol. 48, No. 1, pp. 17-28, 2018. https://doi.org/10.1007/s40279-017-078 6-z.

[11] Memmert, D., Lemmink, K. A. P. M., \& Sampaio, J. Current Approaches to Tactical Performance Analyses in Soccer Using Position Data. Sports Medicine, Vol. 47, No. 1, 2017. https://doi.org/10.1007/s40279-016-0562-5.

[12] Hierro, J. V. L. UEFA Futsal Coaching Manual. Union des Associations Européennes de Football (UEFA), route de Genève 46, 1260 Nyon, Switzerland. 2017.

[13] Lapresa, D., Álvarez, L., Arana, J., Garzón, B., \& Caballero, V. Observational analysis of the offensive sequences that ended in a shot by the winning team of the 2010 UEFA Futsal Championship. Journal of Sports Sciences, Vol. 31, No. 15, pp. 1731-1739. 2013. https://doi.org/10.1080/0264 0414.2013.803584

[14] Roberts, S. J., Rudd, J. R., \& Reeves, M. J. Efficacy of using non-linear pedagogy to support attacking players' individual learning objectives in elite-youth football: A randomised cross-over trial, Journal of Sports Sciences, Vol. 38, No. 1112, pp. 1454-1464, 2020. https://doi.org/10.1080/02640414 .2019 .1609894 .

[15] Sarmento, H., Clemente, F. M., Araújo, D., Davids, K. McRobert, A., \& Figueiredo, A. What Performance Analysts Need to Know About Research Trends in Association Football (2012-2016): A Systematic Review, Sports Medicine, Vol. 48, No. 4, 799-836, 2018. https://doi.org/10.1007/s40279-017-0836-6.

[16] Gómez, M.-Á., Moral, J., \& Lago-Peñas, C. Multivariate analysis of ball possessions effectiveness in elite futsal. Journal of Sports Sciences, Vol. 33, No. 20, pp. 2173-2181, 2015. https://doi.org/10.1080/02640414.2015.1075168

[17] Ostrov, J. M., \& Hart, E. J. Observational methods. In Oxford handbook of quantitative methods (Vol. 1). Oxford University Press New York, NY. 2012.

[18] Spradley, J. P. Participant observation. Waveland Press. 2016.

[19] Navarro, D. J., Newell, B. R., \& Schulze, C. Learning and choosing in an uncertain world: An investigation of the explore-exploit dilemma in static and dynamic environments, Cognitive Psychology, No. 85, pp. 43-77, 2016. http://dx.doi.org/10.1016/j.cogpsych.2016.01.001.

[20] Barada, V. Sarah J. Tracy, Qualitative Research Methods: Collecting Evidence, Crafting Analysis, Communicating Impact, In Revija za sociologiju, Vol. 43, No. 1, 2013. 
https://doi.org/10.5613/rzs.43.1.6.

[21] Courel-Ibáñez, J., McRobert, A. P., Toro, E. O., \& Vélez, D. C. Collective behaviour in basketball: A systematic review, International Journal of Performance Analysis in Sport, Vol. 17, No. 1-2, pp. 44-64, 2017. https://doi.org/10.1080/2474 8668.2017.1303982.

[22] Gómez, M. A., Méndez, C., Indaburu, A., \& Travassos, B. Goal effectiveness after players' dismissals in professional futsal teams, Journal of Sports Sciences, Vol. 37, No. 8, pp. 857-863, 2019. https://doi.org/10.1080/02640414.2018.153 1498.

[23] Méndez-Domínguez, C., Gómez-Ruano, M. A., Rúiz-Pérez, L. M., \& Travassos, B. Goals scored and received in 5vs4 GK game strategy are constrained by critical moment and situational variables in elite futsal, Journal of Sports Sciences, Vol. 37, No. 21, pp. 2443-2451, 2019. https://doi.org/10.1080/02640414.2019.1640567.

[24] Silva, P., Chung, D., Carvalho, T., Cardoso, T., Davids, K., Araújo, D., \& Garganta, J. Practice effects on intra-team synergies in football teams, Human Movement Science, Vol. 46, pp. 39-51, 2016. https://doi.org/10.1016/j.humov.2015. 11.017 .

[25] Jankowski, T. Successful German Soccer Tactics. Meyer \& Meyer Verlag, 2015.

[26] Teoldo, I., Guilherme, J., \& Garganta, J. Training football for smart playing: On tactical performance of teams and players, Appris Editora e Livraria Eireli-ME, 2017.

[27] Oglu, A. R. G., Vladimirovich, G. V., Nikolaevna, F. S., \& Stepanovich, B. V. Optimization of Rehabilitation Effects of Futsal as Part of Comprehensive Correctional and Developmental Program on the Motor, Regulatory and Adaptation Potential of Boy at the Age Of 10-12 With ICP, International Journal of Applied Exercise Physiology, Vol. 8, No. 3, pp. 115-128, 2019. https://doi.org/10.26655/IJAEP.2 019.9.15.

[28] Sturgess, P. Futsal: training, technique and tactics, Bloomsbury Publishing, 2017.

[29] Sukarmin, Y., \& Ndayisenga, J. Evaluation of Burundi Physical Education Teachers, Coaches, and Athletes' Sport Nutrition, Massage, and Physiotherapeutic Exercises Knowledge, International Journal of Human Movement and Sports Sciences, Vol. 8, No. 4, pp. 154-159, 2020. DOI: 10.13189/saj.2020.080408.

[30] Ndayisenga, J. Circuit training intervention for adaptive physical activity to improve cardiorespiratory fitness, leg muscle strength static and balance of intellectually disabled children, Sport Mont, Vol. 17, No. 3, pp. 97-100, 2019. https://doi.org/10.26773/smj.191019.

[31] Ndayisenga, J. The Perception of International Students on the Facility and Sport Tourism Event Management, Sport Mont, Vol. 17, No. 2, pp. 53-58, 2019. https://doi.org/10.26773/smj.190609. 